\title{
The Coordinaling Roles of Management: A Typology for Analysis
}

\author{
GEORGE D. GREENBERG \\ University of Michigan
}

Coordination is traditionally conceived as an ideal which organizations strive to achieve but may not fully attain. The prior specification of a common organizational goal or purpose is assumed and the degree of coordination is measured in terms of integration of activity towards attainment of the goal. For example, Mooney defines coordination as "the orderly arrangement of group effort to provide unity of action in the pursuit of a common purpose."1 Harold Seidman concludes a chapter on coordination by arguing, "If we want coordination, we must first agree on our national goals and priorities and commit the resources required for their accomplishment." 2 More recently, alternative conceptions of coordination have been advanced which do not depend on the prior assumption of agreed upon organizational goals. The purpose of this article is briefly to elaborate alternative conceptions of the process of coordination and to suggest a five-fold typology of the coordinating roles the management of an organization might assume.

According to the more traditional view, organizations, by definition, have shared goals or purposes. According to Mooney, organization is "the form of every human association for the attainment of a common purpose." Simon, Smithburg and Thompson define administration "as the activities of groups cooperating to accomplish common goals."4 However, recent organization theory recognizes the extent to which the presence of agreed upon organizational goals is problematic. Lawrence Mohr notes "many entities that are organizations in the legal sense are only barely organizations in the sociological sense; they are lacking in general com-

George D. Greenberg is an Assistant Professor. of Political Science at the University of Michigan. He has published articles in The American Political Science Review and Public Policy. Currently, he is engaged in a study of the implementation of federal health programs at the state and local level under a grant from the National Center for Health Services Research at HEW.

1J. Mooney, "The Principles of Organization," pp. 84-105 in D. Waldo (ed.) Ideas and Issues in Public Administration (New York: McGraw Hill, 1953), p. 86.

2H. Seidman, Politics, Position, and Power (New York: Oxford University Press, 1970), p. 84.

3lbid., p. 84.

4H. Simon, D. Smithburg, and V. Thompson, Public Administration (New York: Alfred Knopf, 1950), p. 3. 
mitment to outcomes that are truly organizational."5 The "common purpose" which an organization pursues may be no broader than the mutual advancement of the individual purposes of the organization's members. James $Q$. Wilson argues against the assumption that organizations necessarily have unifying goals. "At the very least (the assumption) prejudges the most interesting question - whether, or under what circumstances, an organization will develop and actively work toward any goal other than the satisfaction of the wants of its members."6 Thus, whether an organization possesses shared purposes beyond the principle of mutual individual benefit is a question to be settled by empirical investigation, not by definition.

Once it is recognized that the extent to which organizations possess agreed upon goals itself varies, it becomes important to broaden our conception of coordination. Charles Lindblom has begun this task. According to Lindblom, "A set of decisions is coordinated if adjustments have been made in it such that the adverse consequences of any one decision for other decisions in the set are to a degree and in some frequency, avoided, reduced, counterbalanced, or outweighed."7 Common purpose drops out of this definition and coordination resides in the accommodation or adjustment of individual units to each other so that each gets what it wants. Lindblom argues that coordination can be achieved without the benefit of an hierarchical superior through a process he calls "partisan mutual adjustment." But if we assume an hierarchical superior is often necessary to break deadlocks and arrange compromises among partisans in large organizations, it is clear that he is greatly aided to the extent that he can take advantage of the processes of reciprocity and mutual accommodation Lindblom identifies.

We can, therefore, distinguish two basic forms of coordinative activity, 111 concerting actions to achieve common ends and purposes, and $(2)$ resolving or avoiding conflicts. The first can be illustrated through the metaphor of an orchestra in which each musician obeys the directions of the conductor in order that each part is blended into a harmonious work. The second can be illustrated through the metaphor of a traffic cop who enables motorists to pass safely through a congested intersection. Herbert Kaufman defines coordination in such a way that both forms are included. "(Cloordination means ordering the direction, volume, and

5L. Mohr, "The Concept of Organizational Goal," 67 American Political Science Review (June 1973), p. 477.

6J. Q. Wilson, Political Organizations (New York: Basic Books, 1974.), p. 10.

${ }^{7} \mathrm{C}$. Lindblom, The Intelligence of Democracy $\mathrm{N}$ New York: The Free Press, 1965 ।, p. 154. 
timing of flows of activities, goods and services so that the functioning of one element in a system at least does not prevent or negate or hamper the functioning of other elements, and at best facilitates and assists the functioning of other elements." 8

Where consensus on goals within an organization is high, coordination is likely to consist of integration around the common goal or goals. Where consensus on goals is low, conflict will dominate and coordination is likely to consist of accommodation so that organizational members do not block each other from attaining their individual goals. However, most organizations must perform both types of coordination, since organizations are complex mixtures of conflict in some areas and cooperation in others. We can, therefore, conceive of the two pure forms of coordination as the ends of a continuum with most actual organizations falling towards the center.

The degree of goal consensus or dissensus is not, however, the only organizational factor which will influence the form coordinative activity takes or the extent of coordination of either form achieved. The subsequent discussion will attempt to define several alternative coordinative roles management can fulfill and to show how the successful performance of each varies as organizational conditions differ.

\section{FIGURE I}

\begin{tabular}{|c|c|c|c|c|c|}
\hline \multirow{2}{*}{$\begin{array}{l}\text { Type of } \\
\text { Coordination } \\
\text { Achieved } \\
\text { Coordinative } \\
\text { Roles of } \\
\text { Management }\end{array}$} & \multicolumn{2}{|c|}{ Concerting } & \multicolumn{3}{|c|}{ Resolving Conflicts } \\
\hline & $\begin{array}{l}\text { Spon- } \\
\text { taneity }\end{array}$ & $\begin{array}{l}\text { Per- } \\
\text { suasion }\end{array}$ & $\begin{array}{l}\text { Impo- } \\
\text { sition }\end{array}$ & $\begin{array}{l}\text { Bargaining } \\
\text { and } \\
\text { Inducements }\end{array}$ & $\begin{array}{l}\text { Neutral } \\
\text { Adjudi- } \\
\text { cation }\end{array}$ \\
\hline
\end{tabular}

In Figure I five possible coordinating roles of management are identified. The five roles represent further elaboration of the two forms of coordination already defined, concerting (integration) and conflict resolution. The primary classification (concerting or conflict resolving) is determined by the degree of goal consensus the organization achieves. The secondary classification (the five roles) is determined by the extent to which the minimal conditions specified in the subsequent discussion are present or absent. Together the five roles provide a typology of the various methods by which coordination can be achieved in organizations. The

${ }^{8}$ H. Kaufman, "Organization Theory and Political Theory," 58 American Political Science Review (March 1964), p. 7. 
subsequent discussion elaborates and explains these five conceptualizations of the coordinative role of management.

\section{Concerting.Spontaneity}

Concerting organizational action is easiest when a single, clear organizational goal exists. A goal is a guide to action. A clear goal provides a clear guide to action. It is operational and it tells organization members what to do. A vague or ambiguous goal cannot provide such guidance. The discussion in Simon. Smithburg, and Thompson's Public Administration of two men cooperating to roll a stone best illustrates this. ${ }^{9}$ The group goal $\mid$ in this case to remove the stonel coincides with each individual's goal for the joint effort (again to get the stone off the road) even though $A$ wants to remove the stone so that he can continue his trip and $B$ wants to remove the stone for exercise. ${ }^{10}$ Each person simultaneously adjusts his efforts to the other's. In this example, the goal is clear enough and the organization small enough that cooperation is secured without hierarchy. Both $A$ and $B$ can coordinate without a superior telling them they are really there to roll the stone off the road and not to break it up with a hammer or to blow it up with explosives. Gulick also speaks of coordination which comes about "by the dominance of an idea. which is the intelligent singleness of purpose in the minds and wills of those who are working together as a group, so that each worker will of his own accord fit his task into the whole with skill and enthusiasm."11 Here the management task is minimal. Management may supply the tools so that the workers can go about their tasks. but it will not have to concert activities, as it should be obvious to each individual what to do. In principle, conflict over means in a small organization with unambiguous goals can be resolved by discussion without the intervention of hierarchical superiors.

9lbid., p. 3.

${ }^{10}$ Cartwright and Zander distinguish between organizational goals, the goals of individuals for the organization, and the goals of individuals for themselves, or partisan interests. They argue that organizational goals emerge out of the individual goals for the organization. When widespread consensus among goals for the organization exists, an organizational goal or shared sense of purpose may be said to exist. The process by which the transformation uccurs is not at all clear. If we accept these distinctions, conflict among goals can refer to either the conflict of different individual goals for the organization or to the conflict of partisan interests. See D. Cartwright and A. Zander, Group Dynamics, third edition (New York: Harper and Row), pp. 401-407.

11L. Gulick, "Notes on the Theory of Organization," pp. 3.45 in L. Gulick and L. Urwick (eds.), Papers on the Science of Administration (New York: Institute of Public Administration, 1937।, p. 6. 


\section{Concerting-Persuasion}

Potential sources of conflict exist in any organization, even our rudimentary organization of two members. Once the organization grows large, hierarchy must be called upon to resolve conflicts that formerly could be resolved by face to face discussion. However, as long as a clear unambiguous goal exists, conflict resolution can take the form of persuasion or appeal to the common criterion of judgment. ${ }^{12}$ When a goal is clear and shared, conflict may still exist over the means to achieve it, but principles exist by which to settle disputes over means and around which action can continue to be concerted once disputes over means are resolved. The superior access to information hierarchic position affords is useful to a manager in convincing subunits that a given course of action serves the common goal. When there is a commonly agreed upon standard, conflict is resolved so that action can continue to be concerted in terms of that standard.

In order to maintain a common sense of organizational purpose when conflicts arise, the persuasive and symbolic functions of management have been stressed and the coercive sanctions of hierarchy deemphasized. Earl Latham has written, "If hierarchic authority is a theological fiction, what is the function of the front office of the bureau? It is to provide leadership and judgment. Leadership is essentially guidance, not command. The distinction is important. Guidance assumes an independent motion in the thing guided." 13 According to Latham, the function of management is to foster the latent will to cooperate among subordinate units. Common purpose is assumed to underly the will to cooperate. Integration in terms of it remains the coordinative task of management.

Anthony Downs has described the sources of conflict within large organizations that result in the divergence of individual's goals from each other and from the organization's formal goals. ${ }^{14}$ Such individual goal divergence makes difficult the maintenance of consensus. There are two inevitable sources of conflict in large organizations: conflicts of interest and technical limitations. Conflicts of interest stem from the different personal goals officials pursue and from their different modes of perceiv. ing reality (for example, separate professional perspectives). Even if all officials shared the same personal goals, different modes of perception would lead to conflict. This would be true even if all officials possessed

12March and Simon define this type of persuasion as problem solving. It is to be distinguished from persuasion designed to alter the preferences of antagonists. See J. March and H. Simon, Organizations (New York: John Wiley, 1958), p. 129.

${ }^{13}$ E. Latham, "Hierarchy and Hieratics," pp. 105-116 in D. Waldo, op. cit., p. 111.

${ }^{14}$ A. Downs, Inside Bureaucracy (Boston, Little Brown: 1967), pp. 50-51. 
the same information and uncertainty did not exist. The latter problems constitute the technical sources of organizational conflict.

These ineradicable sources of conflict within large hierarchical organizations produce what Downs has labeled authority leakage. Authority must be delegated in a hierarchy lotherwise the central decision maker is overloaded I. Delegation of authority gives subordinate officials the opportunity to pursue their own goals. "Such leakage is not caused by delegation per se, but by the fact such delegation is accompanied by variance in officials' goals. Delegation of discretion without goal variance would not result in leakage of authority (except through unintentional errors). Hence goal variance among officials is the crucial cause of authority leakage." 15 As divergence among goals develops in large organizations, management is increasinkly faced with the problem of assuring compliance with its own interpretations of what the organization's goals are.

Even a single, clear operational goal will not eliminate authority leakage in a large organization, but it will minimize it and make agreement on what to do easier to obtain. Organizations with single, clear goals therefore fundamentally differ from organizations with multiple, vague goals.

As centrifugal forces build and goals diverge, reliance on persuasion will be inadequate to assure the concerting of organizational activities. But this does not mean that they cannot be coordinated. Other factors will condition the ability of management to resolve conflicts.

\section{Resolving Conflicts}

As goals diverge, conflict resolution increasingly serves the function of enabling each organizational subunit to obtain its own goals. Most organizations both resolve conflicts and attempt to foster a sense of common purpose at the same time. However, for clarity of exposition, let us assume that few, if any, common organizational purposes exist. Conflict resolution within an organization can take three forms: imposition, bargaining, and neutral adjudication. It is important to distinguish these forms and establish the conditions for the successful performance of each.

\section{Conflict Resolution-Imposition}

When there are no clear, shared goals and differences of opinion occur between management and subunits, one method of resolving the conflict is imposition. An imposed solution can attempt to reconcile and take into account differences between subunits' and management's own

15J bid., p. 134. 
goals for the organization, or it can simply implement management's own goals. In either case, management works out the solution and attempts to enforce it, regardless of whether subordinate units approve or not. If management is forced to take subunits' goals into account when working out the proposed solution, we are in the realm of bargaining, not imposition. Subordinate units accept the imposed solutions, because the costs to themselves of disobeying are too great.

Management may attempt to impose a coherent and integrated set of actions on the organization, or it may simply impose solutions on an ad hoc basis as problems arise, thereby resolving the specific conflict. In either case, management must have a clear conception of its own goals. and must have the authority, the will, and the knowledge necessary to impose them. If management is successful in this endeavor, conflict will be suppressed, and, after the fact, it will appear to the outside observer that spontaneous concerting of activity has occurred. For a variety of reasons. these conditions are unlikely to be completely fulfilled. As conflict among goals increases within an organization, it is likely to occur within the top management group as well. Even if top officials remain unified and possess the authority they need to impose solutions on an organization, they may lack the information and technical competence to be confident they have the right solution to impose. And top officials, especially in the public sector, may face a variety of external checks upon their formal authority which may reduce their enthusiasm for attempting to impose whatever solutions they have developed.

\section{Conflict Resolution - Bargaining and Inducements}

When there are no clear, shared goals and differences of opinion occur between management and subunits, a second method of resolving the conflict is bargaining between management and subunits. Instead of the absolute subjection of the adversary, an exchange is sought in which each bargainer achieves some goals at the expense of other goals which are valued less. Management offers inducements to the subunits to cooperate with its goals. Managers of organizations with a large stockpile of slack resources are therefore in a stronger bargaining position than managers of organizations with little disposable surplus. ${ }^{16}$ Inducements can, in turn, be used by subunits to pursue their own goals, until a new conflict occurs either with management or with some other subunit. Alternatively, management may threaten recalcitrant bureaus with sanctions unless cooperative behavior is forthcoming. If the formal authority of

16For a definition of organizational slack, see R. Cyert and J. March, The Behavioral Theory of the Firm (Englewood Cliffs: Prentice-Hall, 1963). 
management is weak, as in some government agencies, sanctions may be no stronger than the threat of withdrawal of previously proffered inducements.

Persuasion is an important bargaining skill. Opponents must sometimes be persuaded that the bargain offered is really to their advantage. We must distinguish this kind of partisan persuasion from persuasion designed to convince people to accommodate themselves to an already agreed upon goal. When Neustadt distinguishes the President's power to command from his power to persuade, he is talking of persuasion as a bargaining tool. ${ }^{17}$ The power to persuade is defined as the President's ability to convince the agencies of government that what he is asking of them is really in their interest. Neustadt implies that even though the President's power to command is limited, through skillful use of his bargaining resources he can quite often achieve his goals.

Management's ability to achieve its interpretation of the organization's goals will vary with its bargaining resources, when goal divergence is high and the conditions for successful imposition are not fulfilled. Bargaining skill is itself a bargaining resource. Some bargainers can parlay meagre resources into larger supplies. Realistically, however, bargainers in initially weak positions will end up with results not out of proportion with the resources with which they started.

\section{Conflict Resolution - Neutral Adjudication}

Often, when organizational goals diverge the most relevant conflicts are between organizational subunits. Management may be neutral among subunits or it may lack the resources either to impose its own goals or to maintain a strong bargaining position in a multi-sided argument. In such circumstances management can still achieve a modicum of conflict resolution by assuming the role of neutral adjudicator. Neutral adjudication can take two forms: arbitration and mediation. As arbiters, hierarchical superiors refrain from taking positions before a dispute is brought to them for resolution, and they retain authority to resolve the dispute on the merits (as they perceive them) if the contending parties cannot eventually agree. Their knowledge of the preferences of both parties may help disputants find mutually agreeable terms.

There is a certain tension between the roles of arbiter and mediator. To the extent that the hierarchical superior retains authority to settle disputes on his own terms, subunits will be less likely to trust him with confidences when he attempts to act as a mediator. Moreover, subunits will

17R. Neustadt, Presidential Power (New York: John Wiley, 1960 ). 
remember past encounters when the superior attempted to impose solu. tions on them or when he took bargaining stances. But to the extent that the arbiter can avoid becoming identified with a position, he encourages subordinates to resolve disputes among themselves if at all possible. Otherwise the arbiter may resolve the conflict on terms less advantageous to a subunit than it could have obtained for itself if it were willing to compromise. In this manner, the presence of an arbiter can theoretically produce a great deal of conflict resolution within an organization, even though few conflicts are ever formally resolved by him. If he happens to take a position beforehand, the subunit favored will not compromise and will prefer to have the dispute settled.

Herman Somers describes how Jimmy Byrnes, director of the Office of War Mobilization, adopted this decision making posture even though he was in a strong position as a manager. "It was one of Byrnes' major accomplishments that public disputes among government officials were kept to a minimum. He performed the role of arbiter or adjudicator with rare skill and effectiveness ... By remaining aloof, OWM would not be committed to a position at an early stage and would not be handicapped if later called upon to make the final decision."18 Edward Banfield's description of Mayor Daley's decision making style is similar. ${ }^{19}$ Even though Daley possesses a great deal of influence, he withholds his judg. ment until the line up of political forces on a question becomes clear. According to Banfield, this minimizes the unnecessary expenditure of hard earned bargaining resources and increases the amount of information available as to the true preferences of others, since they are willing to commit resources only to those causes they really care about.

A strong decision maker can choose to play the role of arbiter for the advantages it can provide. However, when the conditions of other coordinative roles remain unfilled, it may be the only one left to play.

Arbiters, however, remain neutral only up until the point of decision, when they necessarily determine the outcome, lending their weight to one side or the other. Since arbiters retain authority to settle disputes they can take advantage of the adjudicative posture to advance their own needs and goals. ${ }^{20}$ On the other hand, the sole job of the mediator is to find a

18H. Somers, Presidential Agency /Cambridge: Harvard University Press, 1950।, pp. 60-62.

${ }^{19}$ E. Banfield, Political Influence (New York: The Free Press, 1961) , pp. 307-324.

20 For a discussion of how an adjudicative process can possibly be shaped to serve the President's need for an expanded consideration of options in the field of foreign policy, see A. George, "The Case for Multiple Advocacy in Foreign Policy Making," of American Political Science Review ISeptember 19721, pp. 751-786. 
mutually satisfactory solution among antagonists. His own interests, or the interests of other parties, do not enter the decision process. He does not possess the ability of the arbiter to adjust or correct any unjust outcomes of the bargaining process. The mediator simply ratifies and advances the goals of whatever coalitions emerge during the discussion process. The successful performance of the role depends solely upon the mutual recognition of organizational participants that it is in their own individual interests to foster accommodation through mediation.

At this point there are no longer any organizational representatives of any goals beyond the mutual advancement of the partisan interests of the members of the organization mediation serves. If management chooses to take the role of representing and advancing the partisan interests of the organization members, the organization drops out of sight and only the partisan interests remain. We have reached the other end of the continuum. Coordination becomes pure conflict resolution and avoidance.

\section{Conclusion}

In order to clarify the possible coordinative roles management can play, a number of conceptual distinctions have been made. The roles defined overlap to some extent and the management of any large organization must play all of them at one time or another. Management sometimes achieves coordination by bargaining, sometimes by adjudicating, sometimes through the formulation of common purposes, sometimes by attempting to impose its own solutions. The presence or absence of the conditions necessary for the successful performance of each of these roles is usually a matter of degree. Clarity of goals, multiplicity of goals, formal authority, size, bargaining resources, etc., vary from organization to organization. As the conditions vary, one of the coordinative roles may predominate even though all are performed to some degree.

Coordination no longer appears to be a simple matter of degree, of more or less. It is a complex task which can be achieved in several ways depending upon the character of the organization which is to be coordinated. As organizational conditions vary, not only the degree of coordination, but also the managerial role by which coordination is achieved, also varies. It is unrealistic to expect management to rely on coordinative roles which are ill-suited to the particular organizational settings it confronts. Now that the forms that coordination can take have been delineated, we are in a better position to explore relationships between organizational settings, the type of coordination attempted, and the degree of coordination achieved. 